\title{
The Challenges Hindering the Promotion of a Culture of Integrity at Jordanian Universities
}

\author{
Esraa Fwzi Mustafa Abu Amshah \\ $\&$ \\ Prof. Mohammed “Amin” Hamed Al-Qudah
}

\begin{abstract}
The present study aimed to explore the challenges hindering the promotion of a culture of integrity at Jordanian universities from the perspective of faculty members. The sample consists from faculty members because faculty members play a significant role in promoting values among students and developing society. The sample consists from 30 faculty members who work in Jordanian universities. It was found that there are several challenges hindering the promotion of a culture of integrity at Jordanian universities. Such challenging include: nepotism. It was found that there are social challenges hindering such promotion. The severity of the latter challenges at Jordanian universities in remote areas is greater than the counterpart severity at Jordanian universities in other areas. The challenges hindering such promotion include: having materialistic employees and the lack of resources at Jordanian universities. They include: failure to recruit highly qualified employees who are capable of promoting integrity in various areas. Faculty members at Jordanian universities play the most significant role in addressing these challenges. They play the most significant role in reducing the severity of the impacts of those challenges. They play the most significant role in improving the educational process. Jordanian universities have wise leaders who run universities in accordance with integrity standards. They meet various educational standards that are related to transparency, justice, accountability and equality in terms of opportunities. The researchers recommend meeting educational standards to promote a culture of integrity in public Jordanian universities. They recommend providing more courses that promote integrity among people in society. These courses should be provided at the centers that aim at establishing family-community partnerships. The researchers recommend conducting more studies that aim at promoting integrity. Conducting such studies shall contribute to meeting the vision of the Integrity and Anti-Corruption Commission. It shall contribute to meeting the vision of the initiatives launched by the latter commission in 2019 in Jordanian universities.
\end{abstract}

Keywords: Jordanian universities, Culture of Integrity

DOI: $10.7176 / \mathrm{JEP} / 11-16-17$

Publication date: June 30th 2020

\section{Introduction:}

Integrity is significant value. Having integrity contributes to the development of societies in all areas. Integrity involves honesty and adherence to moral and ethical principles when dealing with people. It serves as an intellectual principle. The way one perceives integrity is determined by his/her principles and values. Integrity may be shown by a specific person, society, institution, or body. It may manifest through a specific behavior. It may manifest in a situation. It is connected with mastering works. It's linked with loyalty, dedication, and accuracy in doing tasks. It is connected with holding oneself accountable for failure. It is connected with giving work priority. Promoting integrity is a goal sought by leaders in universities, schools, public bodies, ministries, and private institutions (Al-Shami \& Al-Qudah, 2020; Al-Tamimi \& Al-Qudah, 2019; Ben Tarif and Al-Qudah, 2019; Jbara and Al-Qudah, 2018; Al-Turk and Al-Qudah, 2017, Hatahet \& Alqudah, 2016, Rahamneh, AlQudah, 2016, Hatahet \& Al Qudah, 2016; Hatahet \& Al Qudah, 2016; Al-Hilat et al., 2008; Al-Qudah, 2006, Jasem and Sabri, 2015).

Due to the significance of showing integrity, several legislations were enacted for promoting integrity and fighting against corruption. Despite that, these legislations are not effective in meeting those goals. These legislations aim at holding corrupted people accountable. They aim at creating a positive organizational culture that is based on integrity. The latter culture must be an anti-corruption culture. Creating such a culture is affected by several factors. Such factors include: how prudent the recruitment process is. They include: the extent of effectiveness of the internal administrative practices. Such practices must be fit with the policies and vision of the institution. Such factors include: the amount of training provided for instructors in order to promote integrity among them. The aforementioned culture can be created through developing a code of ethics at the institution.

Addressing corruption requires achieving social justice. It requires making reforms to the wage system. It requires fighting against poverty and unemployment. It requires establishing an anti-corruption culture (Al-Sen, 2011). To fight against corruption, societies -including the Jordanian society- are keen on raising up good citizens and promoting values among them. They aim at fighting against corruption through promoting collaboration among families, schools and media and civil society institutions. If these parties do their duties 
effectively, the culture of societies shall develop and ethics shall be promoted. Educational institutions aim at promoting ethics and raising up good citizens who are keen on serving their societies.

To fight against corruption, educational institutions are keen on creating a code of ethics that includes the rules of the workplace. The code of ethics at any educational institution should aim at raising the productivity of employees (Al-Zoby \& Al-Qudah , 2020 Fallouh \& Al-Qudah , 2020, Mohammad \& Al-Qudah, 2020; AlHammad \& Al-Qudah, 2019, Malkawi, \& Al-Qudah, 2018:2, Malkawi, \& Al-Qudah, 2018, Al-Qudah, 2017; Hamadneh and Al-Qudah, 2017 ،and Naser, 2004).

The Integrity and Anti-Corruption Commission in Jordan is keen on cooperating with universities. Such cooperation aims at promoting values, including integrity. It aims at fighting against corruption in universities. Through such cooperation, several projects were launched. These projects are listed in the National Strategy for Integrity and Anti-Corruption. They include: a project that aims at promoting awareness among faculty members about the significance of integrity and anti-corruption. The latter project aims at promoting collaboration between the Integrity and Anti-Corruption Commission and the faculty members who work at Jordanian universities. It aims at improving the relationships between those faculty members and the aforementioned commission. It aims at encouraging faculty members to deliver awareness raising-messages to students about the significance of integrity and anti-corruption through using all the available means. It aims at fighting against corruption through creating an anti-corruption environment and promoting awareness about the negative impacts of corruption. It aims at fighting against corruption through addressing the shortcomings existing in the relevant legislations. It aims at fighting against corruption through encouraging civil society organizations to establish partnerships with each other. It aims at fighting against corruption through coordinating the efforts exerted by institutions. It aims at fighting against corruption through improving the capabilities of the staff in institutions (Al-Rai, 2019).

Integrity plays a significant role in improving the educational system. It must be existent in each element of the elements of the educational system. Such elements include: faculty members, students, and administrators. The aforementioned commission developed a strategy for the years (2017-2025). The latter strategy includes several standards and requirements of integrity. It aims at promoting integrity in society. It aims at preventing corruption through creating an anti-corruption environment. It aims at meeting such goals through promoting knowledge in Jordanian universities about the integrity standards. Such standards include: standards that are related to the rule of the law, accountability, transparency, justice, equality, governance and equality in terms of opportunities.

Based on the modern educational trends, promoting integrity is a strategic goal that must be met in order to achieve development. Promoting integrity shall contribute to the promotion of partnerships between institutions and people in society. Based on the modern educational trends, an educational system can't meet the intended goals without adhering to all its principles.

Jordanian universities have been showing a poor performance in promoting awareness about the significance of academic integrity in campus. They haven't been enforcing punishments in a fair manner. They have been refraining from providing incentives and rewards to their partners in the initiatives that aim at promoting academic integrity in campus. These things led to increasing the number of the violations committed against the customs and traditions in the academic field.

The duties of faculty members aren't limited to the delivery of correct information to students. In fact, they include: guiding and educating students. They include: adjusting students' behaviours and way of thinking (AlHayali, 2013, 334). According to Alkayed \& Alqudah (2019) and Al-Harbi (2017), adherence to ethics plays a significant role in enabling individuals, institutions and societies to achieve success. Adherence to ethics play a significant role in organizing human relationships and doing daily life tasks and duties well. All professionals must adhere to ethics. That is because adhering to ethics plays a significant role in enabling professionals to do their duties well and track the development of their performance and capabilities.

Administrators and faculty members at universities should address issues related to ethics (e.g. integrity). They should serve as a role model for others. Thus, people should look up to them when making decisions and performing practices. In order for administrators and faculty members at universities to address integrity-related issues effectively, they must have adequate knowledge about integrity. It should be noted that administrators at universities must have integrity when taking any academic or administrative measure. The latter administrators must have integrity when delivering any service to faculty members, students or any other party. 
In order to promote a culture of integrity in universities, there are several requirements that must be met. Such requirements must be met by the university president, administrators, faculty members, students and employees in the campus. Hence, the present study sheds a light on the organizational and academic requirements that must be met to promote a culture of integrity in universities.

Integrity is represented in showing adherence to ethics and preserving the public resources and possessions. It involves fighting against corruption. It involves having honesty, and refraining from causing harm to others (AlDuwaik, 2013: 10). It involves having academic and intellectual honesty, especially when using, transferring, documenting, and publishing information. It refers to having academic and intellectual honesty when conducting research and managing projects. It involves adhering to ethics by instructors, students and employees in educational institutions and civil society organizations. Such adherence shall regulate their lives, and behaviours. Academic integrity involves fighting against cheating acts in exams. It involves fighting against the acts of plagiarism. It involves ensuring that students aren't submitting projects that are carried by others (Fadloon, 2017). It involves fighting against corruption in academic areas.

As for organizational integrity, it involves adherence to morals in organizations. Such morals include: morals related to accountability, commitment, self-control and etc.. Having a high organizational integrity level in organizations shall improve the performance of organization (Al-Ta'I et al., 2017).

Administrators and faculty members at universities must have adequate knowledge about integrity. They must show much integrity when making decisions and carrying out practices. They must show academic and organizational integrity. That shall contribute to having good outcomes and fighting against various types of corruption. In the light of the aforementioned information, the present study aimed to explore the challenges hindering the promotion of a culture of integrity at Jordanian universities from the perspective of faculty members.

\section{Statement of the Problem and the Study's Questions:}

Due to openness, cultural diversity exists in all societies today. Hence, it is necessary to explore the extent of adherence to morals by the members of each society. It's necessary to explore that, because such adherence shall deter people from committing immoral acts. Due to the spread of nepotism in all social and educational institutions, several challenges have been facing the delivery of education. Such challenges negatively affect the educational process. In order for universities to excel and overcome challenges, they must have wise leaders of integrity. They must be fair and show a high level of transparency.

It should be noted that universities play a major role in fighting against corruption. Therefore, the management of universities should develop and implement strategies that aim at fighting against corruption. The University of Jordan aims to complement the role of the Integrity and Anti-Corruption Commission in Jordan. Therefore, it joined an initiative that is launched the latter commission, the Jordanian Transparency Centre and the United Nations Development Program(UNDP) in Arab States. The latter initiative is named (anti-corruption universities). In addition to the University of Jordan, 12 Jordanian public and private universities joined the latter initiative. The latter initiative aims at promoting awareness among youth in university about the significance of fighting against corruption. It aims at enabling youth in university to fight against corruption. That is because the Jordanian government incurs much loss that is attributed to corruption. It's because corruption hinders development in Jordan. In the light of the aforementioned information, the present study aimed to explore the challenges hindering the promotion of a culture of integrity at Jordanian universities from the perspective of faculty members. It aimed to offer answers to the following questions:

Q.1. What are the contributions of the Jordanian universities in terms of promoting a culture of integrity from the perspective of faculty members?

Q.2. . What are the challenges hindering the promotion of a culture of integrity at Jordanian universities from the perspective of faculty members?

\section{The Study's Objectives:}

The present study aimed to:

1- $\quad$ Identify the contributions of the Jordanian universities in terms of promoting a culture of integrity from the perspective of faculty members

2- Identify the challenges hindering the promotion of a culture of integrity at Jordanian universities from the perspective of faculty members. 
The Study's Significance:

-Theoretical significance:

The present study is significant due to the following reasons:

-As far as the researchers know, there aren't many studies that shed a light on the promotion of a culture of integrity in Jordanian universities.

-The present study aimed to shed a light on the role of universities in promoting values in order to fight against corruption. Such values include: values related to integrity, transparency, and organizational justice. Promoting such values by universities requires having effective leadership that is capable of meeting the requirements of integrity.

-The present study aimed to shed a light on a very important topic. It offers useful knowledge to academic leaders, students and administrators at universities. It is significant due to the significance of fighting against corruption and promoting a culture of integrity by universities in general and the University of Jordan in particular.

-Practical significance:

The present study is significant because it is beneficial for the following bodies and institutions:

- Jordanian universities: The present study is significant because it aimed to explore the contributions of the Jordanian universities in promoting a culture of integrity. It is significant because it aimed to explore the challenges hindering the promotion of a culture of integrity in Jordanian universities.

-The Integrity and Anti-Corruption Commission: The present study is significant because it provides the latter commission with evidence-based information about the challenges hindering the promotion of a culture of integrity in Jordanian universities.

-The Ministry of Higher Education in the Hashemite Kingdom of University: The present study is significant because it promotes partnerships between the latter ministry and the aforementioned commission in terms of implementing the National Strategy for Integrity and Anti-Corruption. It encourages universities to provide students with a course about integrity. It suggests that Jordanian universities should address the challenges hindering the promotion of integrity in the educational process.

-The present study provides researchers with a theoretical framework that enables them to do studies. It provides decision makers at ministries and universities with significant information.

\section{The Study's Limits:}

The study's limits are listed below:

- Thematic limits: The present study aimed to explore the challenges hindering the promotion of a culture of integrity at Jordanian universities

- Human limits: The researchers selected a sample that consists from several faculty members who work in Jordanian universities.

- Spatial limits: The present study was conducted in several Jordanian universities

- Temporal limits: The present study was conducted during the second semester of the academic year $(2019 / 2020)$.

\section{The operational definitions:}

The operational definitions of the study's terms are presented below:

Challenges: They refer to the problems and barriers that hinder educational institutions from meeting their intended goals. The severity of these challenges are measured through using the study's questionnaire.

The culture of integrity: It refers to the adherence to morals by faculty members and students in Jordanian universities. It is explored through using the study's questionnaire.

\section{Previous Studies:}

The researchers of the present study reviewed several studies that shed a light on the study's topic. Some of those studies are published in Arabic language and the rest are published in English language. The researchers of the present study commented on these studies after reviewing them. These studies are presented below based on the year of the publication. They are presented below from the oldest to the newest ones:

Al-Harbi (2012) aimed to explore the extent of showing administrative transparency by faculty members and administrators in the faculty of education at King Saud University. The sample consists from 410 members and administrators. The descriptive analytical approach was adopted. It was found that the extent of showing administrative transparency by faculty members and administrators in the faculty of education at King Saud University is moderate. It was found that the extent of meeting the requirements of administrative transparency is 
high. It was found that there are statistically significant differences between the respondents' attitudes in the area of showing internal transparency which can be attributed to (the nature of the work). It was found that there isn't statistically significant difference between the respondents' attitudes which can be attributed to academic qualification.

Al-Heyali (2013) address the role of faculty members in promoting integrity and transparency and fighting against corruption in Mousel University. He adds that transparency is a modern concept that emerged due to major developments in various areas. He adds that faculty members aim at addressing current and potential problems in society. In order for faculty members to address problems effectively, there are several requirements that must be met. For instance, faculty members must plan the way of covering the curriculum throughout the semester. They must adhere to morals and ethics when dealing with students. They must utilize any potential mean for promoting transparency and integrity among students. An inductive approach was adopted by the latter researcher. The latter researcher recommends providing academic leaders and faculty members with training courses and workshops that enrich their knowledge about their roles and duties. He recommends improving the relationship between Iraqi universities and the Integrity Commission. He recommends creating an anti-corruption culture. He suggests that this culture must aim at meeting the national interests and promoting national security. He suggests that this culture must be based on customs, traditions, morals, social values, and religious principles.

Jasem and Sabri (2015) shed a light on integrity in university education. They shed a light on the impacts of providing university students with knowledge about integrity through the public relations course in the faculty of media. They suggest that public relationships must be based on integrity, credibility and transparency. They add that promoting integrity, credibility and transparency among students requires carrying out training activities throughout the public relations course. The sample consists from 208 female and male students who were selected from the public relations department. Those students are selected from second year and third year students. They were enrolled in a public relations course through an open learning system. It was found that most of the students have adequate knowledge about anti-corruption, transparency and integrity. It was found that most of the students have adequate knowledge about the public relations course that promotes transparency and integrity.

Al-Harbi (2016) aimed to explore the extent of having academic integrity by female and male undergraduates and postgraduates in Saudi Arabia. He aimed to explore the relationships between academic integrity from one hand and ethical responsibility, academic self-efficacy, motivation, learning strategies, test anxiety, and GPA from another hand. He aimed to explore whether there are significant differences between the respondents in terms of the extent of having academic integrity which can be attributed to the type of academic program, or university. The sample consists from 357 female and male undergraduates and postgraduates. It was found that the extent of having academic integrity by female and male undergraduates and postgraduates in Saudi Arabia is high in all the six areas jointly and separately. It was found that there isn't any statistically significant difference between the respondents in terms of the extent adhering to the academic integrity standards which can be attributed to university. It was found that there is a statistically significant difference between undergraduates and postgraduates in terms of the extent adhering to the academic integrity standards in five academic integrity areas. It was found that there is a statistically significant difference between the respondents' in terms of the extent of having academic integrity which can be attributed to the type of academic program. It was found that there is a significant correlation between academic integrity from one hand and ethical responsibility, academic self-efficacy, motivation, learning strategies, test anxiety, and GPA from another hand.

Al-Mbaideen and Al-Anati (2017) aimed to explore the role of Jordanian universities in promoting integrity. They aimed to explore the relationship between integrity and national loyalty among public and private university students. The sample consists from 846 female and male university students. Those students were selected from the University of Jordan and Al-Ahliyya Amman University. They were selected through using the random stratified sampling method. It was found that the role of Jordanian universities in promoting integrity is moderate in the study's areas (i.e. transparency, accountability, and collaboration). It was found that national loyalty level of the respondents is high. It was found that there are differences between the respondents in terms of the extent of showing integrity which can be attributed to the type of the university. The latter differences are for the favor of the ones enrolled in a private university. The latter researchers recommend promoting integrity among students in Jordanian universities. They recommend encouraging students in Jordanian universities to engage in activities and enroll in cultural clubs.

Bani Sakher (2017) aimed to explore the extent of practicing ethical leadership by the heads of departments in 
Jordanian universities. He aimed to explore the relationship between the extent of practicing ethical leadership and the organizational integrity level among the latter heads of departments. The population consists from all the faculty members who work in the Hashemite University, Yarmook University, and Mu'tah University. These universities are public universities. The Hashemite University is located in the Central Province and Yarmook University is located in the Northern Province. Mu'tah University is located in the Southern Province. To be specific, the population consists from 1612 faculty members. The sample was selected through using the random stratified sampling method. It consists from 246 faculty members. The latter researcher conducted the study during the academic year (2015/2016). The sample represents $15 \%$ of the study's population.

It was found that the extent of practicing ethical leadership by the heads of departments in Jordanian universities is high from the faculty members' perspective. It was found that there isn't any statistically significant difference between the respondents' attitudes in terms of ethical leadership which can be attributed to gender, academic rank and the country of graduation. It was found that there is a statistically significant difference between the respondents' attitudes in terms of ethical leadership which can be attributed to the university. The latter difference is for the favor of the ones who work in the Hashemite University. It was found that the organizational integrity level of the heads of departments in Jordanian universities is high. It was found that there isn't any statistically significant difference between the respondents' attitudes in terms of organizational integrity which can be attributed to the academic rank, or year of graduation. It was found that there are statistically significant differences between the respondents' attitudes in terms of organizational integrity which can be attributed to gender and university. The latter difference is for the favor of males and the ones enrolled in the Hashemite University.

Brenda and Anastassiya (2018) aimed to explore the effectiveness of educational programs in promoting academic integrity in the University of Manitoba in Canada. They selected a sample that consists from several students. The sample includes: US, Australian, Sweden, Qatari and Taiwani students. Qualitative and quantitative approaches were adopted. It was found that there are several methods that can be used for fighting against the academic misconduct. Such methods include: providing students with knowledge about the proper way of citation. They include fighting against plagiarism. It was found that integrity can be promoted through holding short sessions and using the internet. That can be done through offering online training courses.

Eaton, and Edino (2018) aimed to improve the role of the research agenda in promoting educational integrity in Canada. They aimed to improve the mechanisms used for promoting educational integrity in Canada. They aimed to meet the study's goals through reviewing the relevant literature. They adopted an analytical approach. They used several databases, such as: ERIC, ProQuest and Google Scholar. They mainly used the databases the publish studies in the fields of education and social sciences. It was found that there are shortcomings in the preventive measures taken in Canada against any integrity violation. It was found that the research in Canada lacks integrity.

Denisova (2018) suggests that there corruption is prevalent in higher education institutions. He adds that the academic integrity level in higher education institutions is very low. He sheds a light on ethical issues in the latter institutions. He aimed to provide an answer to the following question: (What can be done in Bologna to fight against corruption and raise the academic integrity level in higher education institutions?) The latter researcher aimed to identify the challenges that hinder universities from cooperating with civil society organizations in terms of fighting against corruption. He aimed to identify the instruments and practices that can raise the academic integrity level in higher education institutions. He aimed to identify whether the latest studies can contribute to increasing the extent of having political dialogue in Bologna. A survey was conducted during the period (2015-2017) in the countries that belong to Bologna, such as: Ukraine. Through this survey, it was found that the number of online cheating acts has been increasing. It was found that it's necessary to acknowledge the existence of corruption in order to offer suggestions for fighting against it. Such a problem can be addresses in Bologna through using all the available means.

\section{Comments on the aforementioned studies}

Through reviewing the aforementioned studies, it can be concluded that faculty members play a significant role in promoting integrity. That is suggested by Al-Harbi (2012). The latter researcher aimed to shed a light on transparency. As for the present study, it sheds a light on various requirements and transparency. Al-Hayali (2013) aimed to shed a light on transparency and anti-corruption. He recommends improving the relationship between universities and the Integrity Commission. He recommends creating an anti-corruption culture. The present study aimed to achieve these goals. It also aimed to promote a culture of academic and organizational integrity. It is similar to the study of Jasem (2015) in terms of the instrument used for promoting a culture of 
integrity. Jasem (2015) suggests that there must be a course that promotes transparency, credibility and integrity. The present study differs from the study of Jasem (2015) in terms of the sample. It selects a sample that consists from several faculty members and students. Jasem (2015) selects a sample that consists from several second and third year students in the public relations department.

The present study is similar to the studies of Al-Harbi (2016) and Al-Mbaideen and Al-Anati (2017) in terms of the subject. To illustrate more, the studies of Al-Harbi (2016) and Al-Mbaideen and Al-Anati (2017) shed a light on the role of integrity in promoting national loyalty and adherence to morals among students. The present study aimed to promote integrity among faculty members and students. It aimed to explore the challenges hindering the promotion of a culture of integrity at Jordanian universities.

Bani Sakher (2017) aimed to explore the extent of practicing ethical leadership by the heads of departments in Jordanian universities. He aimed to explore the relationship between the extent of practicing ethical leadership and the organizational integrity level among the latter heads of departments. The researchers of the present study aimed to explore that through using a questionnaire and conducting interviews with faculty members. The latter questionnaire measures the extent of showing integrity by faculty members.

Denisova (2018) aimed to explore the reality in Bologna. He aimed to explore the extent of prevalence of corruption in higher educational institutions. He aimed to explore the academic integrity level in higher educational institutions. He aimed to shed a light on ethical issues in the latter institutions. He aimed to offer solutions for fighting against corruption. Similar to the study of Denisova (2018), the present study aimed to identify the requirements that must be met for promoting a culture of integrity. Meeting such requirements shall contribute to addressing the challenges hindering such promotion in public universities in Jordan.

Reviewing the aforementioned studies enabled the researchers to develop the theoretical framework. The latter framework sheds a light on academic and organizational integrity. It sheds a light on the challenges hindering the promotion of a culture of integrity at Jordanian public universities. Reviewing the aforementioned studies enabled the researchers to choose the most suitable statistical analysis methods and the study's approach. It enabled the researchers to develop the study's instrument and interpret the study's results.

\section{Method and procedures}

\section{Study methodology:}

The study aims to reach the challenges and obstacles that prevent the development of a culture of integrity in Jordanian universities, and to achieve this goal, a qualitative approach (case study) will be used by conducting in-depth interviews using an open question form intended to delve deeper to identify the challenges and obstacles that prevent development A culture of integrity at the University of Jordan, and analysis of data related to the study to access the required information, with the aim of understanding and knowing some of the issues and points whose location is known only to the members of the sample for the current study.

\section{Study personnel:}

Three official universities will be selected in the Hashemite Kingdom of Jordan (University of Jordan, Yarmouk University, Mu'tah University). Intentionally, as it is, from the researchers 'point of view, representative of the study sample on the central, northern, and southern regions, which includes educational competencies represented in developing a culture of integrity, and (30) faculty members were interviewed.

\section{Study instrument:}

The researchers built open questions to ask study members during interviews, take notes, and monitor results. The aim of these interviews is to obtain the view of faculty members and academic leaders at the University of Jordan on how to overcome these challenges and obstacles through the proposed educational requirements that must be met at the university.

\section{Validate the study instrument:}

To verify the sincerity of the tool, the questions are distributed in their initial form to a group of experts, arbitrators and specialists in the educational field at the University of Jordan with the aim of expressing their opinion on the open questions of the interviews, in terms of clarity of meaning and linguistic wording and the extent of their suitability to the field to which it belongs, and any adjustments and observations they see appropriate. Notes will be taken $80 \%$ of two judgments in order to achieve the objectives of the study.

The stability of the study tool: To achieve consistency, an interview was chosen for a faculty member and 
written in writing, the answers were analyzed and presented to the individuals interviewed, and they expressed their approval of the analysis provided to meet them.

\section{The results of the study and its discussion:}

The first question: What is the role of the University of Jordan in developing a culture of integrity from the viewpoint of faculty members? To answer this question, the interviews were analyzed, iterations were calculated and percentages were extracted.

\section{First: From the viewpoint of faculty members:}

The results of the analysis of the interview showed the faculty members in the official Jordanian universities under study, an agreement that the concept of integrity in universities is determined by the criteria on which academic integrity is based and is within three levels: the university level, the level of scientific material and marks, and the level of dealing with students, and this is due to the fact that Integrity takes place through interconnected processes and not through one party alone, but it is an existing culture, but it needs to be constantly developed and updated, and when the interviewers are asked about the concept of integrity they have, their answers revolve around "transparency and justice and giving everyone with their right according to the prevailing instructions, regulations, laws and academic norms." The answers of the interview sample as shown in Table (1), on the criteria of honesty, truthfulness, transparency and justice in administrative work and evaluation, and the proportion of faculty members agreed on the concept of integrity through its standards by $46 \%$ on this concept and came at a high rate depending on that integrity is the achievement of justice, transparency and accountability Equal opportunity means applying standards that measure its existence.

Among the concepts agreed upon by faculty members about the concept of integrity is "commitment to administrative instructions, regulations and laws without discrimination, and away from racial, intellectual or regional affiliations", which emphasizes the ethical dimension and that integrity is based on a value system with a faith reference, as it includes commitment to time The content and content provided to students, the student's academic freedom and respect for opinion and other opinion. The faculty members 'agreement was approximately $40 \%$. This is confirmed by the moral responsibility and self-discipline of the individual. The commitment to integrity and its application in all fields relates to the values and ethics represented in teaching by example.

The results of the interview also showed that what enhances integrity through its concept among faculty members is to emphasize the self-responsibility of the faculty member towards himself first, as it has a greater role in developing a culture of integrity through direct impact on students, "it is the responsibility towards selfdevelopment to provide academic work to the fullest "13.13\% of the faculty members who gave the self a major responsibility in achieving integrity and developing it in their universities came, which leads to the question about the low percentage of the concept of integrity in terms of self-responsibility for the faculty member, and is there really a weakness in the self-development towards himself, which is reflected on the process The educational, social, and cultural process for developing integrity and practicing its values heart and mind to affect the university community, including its administrators, academics and students.

Table (1) the concept of academic integrity from the viewpoint of faculty members.

\begin{tabular}{|l|l|l|l|}
\hline & What is the concept of academic integrity? & Repetitions & percentage \\
\hline $\mathbf{1}$ & $\begin{array}{l}\text { Transparency, fairness, and giving everyone his right according to } \\
\text { the prevailing academic norms. }\end{array}$ & $\mathbf{1 4}$ & $\mathbf{4 6 \%}$ \\
\hline $\mathbf{2}$ & $\begin{array}{l}\text { Adherence to administrative instructions, regulations and laws } \\
\text { without bias. }\end{array}$ & $\mathbf{1 2}$ & $\mathbf{4 0 \%}$ \\
\hline $\mathbf{3}$ & $\begin{array}{l}\text { It is the responsibility towards self-development to fully deliver } \\
\text { academic work. }\end{array}$ & $\mathbf{4}$ & $\mathbf{1 3 . 3 3 \%}$ \\
\hline Total & & $\mathbf{3 0}$ & $\mathbf{1 0 0 \%}$ \\
\hline
\end{tabular}

As for the existence of academic integrity in the official Jordanian universities, the results of Table (2) show a variation in the percentage of academic integrity in universities, as it saw a rate of $43.33 \%$ of the study sample that there is fairness to some extent. Against the percentage of $36.66 \%$, you see that academic integrity is present in a very large way, while $20 \%$ of the study sample saw the lack of academic integrity, and some members of the study sample attributed this difference in relation to the presence of a fundamental difference between the university and university and the degree of their influence in the environment surrounding the university, so some universities are affected Jordanian within the sample of the study by the pressures exerted on it at the level 
of departments and faculty members, whether tribal pressures or pressure from the owners of positions and career centers, which represents a disadvantage in integrity, what makes it fall within the scope of integrity, while a percentage of faculty members confirmed that there is integrity that is set Through the specialized committees, and they are present in a large percentage among administrators. Some members of the sample saw that integrity depends on the person's concept and his interpretation of some matters when it is in his favor or not, and this follows the quality of some faculty members in terms of (creation, knowledge, knowledge, commitment) and if not Integrity exists, as it is individual cases that are dealt with according to the law through warnings, dismissal and judicial authorities, because according to one of theme's opinion that "the most interacting things with academic integrity are the issues A personality represented by you believes in the value of integrity as it raises the efficiency of work and employees in the environment in which it operates. It is worth noting that the individuals of the sample who indicated that there is no integrity have been exposed to positions that confirm their point of view, whether at the administrative level in terms of appointments and promotions and the preservation of the leadership position that the individual may obtain, or that he exploits it in favor of the academic process is honest in all aspects or deny this attribute Which leads to corruption and an administrative defect that affects the performance and progress of the educational process on the one hand, as it may be at the level of students and the acceptance of those who do not fit or rise academically to higher studies and bias for tribalism, which leads to weak outputs that represent the official Jordanian universities. The answers of the sample of the interview were as illustrated in Table (2), and the ratios were as follows:

Table (2) In your opinion, is there an academic integrity in the official Jordanian universities? The degree to which the values of integrity (justice) are applied

\begin{tabular}{|l|l|l|l|}
\hline & $\begin{array}{l}\text { Do you think there is academic integrity in } \\
\text { public universities? }\end{array}$ & Repetitions & percentage \\
\hline $\mathbf{1}$ & There is fairness to some extent. & $\mathbf{1 3}$ & $\mathbf{4 3 . 3 3 \%}$ \\
\hline $\mathbf{2}$ & There is very much integrity. & $\mathbf{1 1}$ & $\mathbf{3 6 . 6 6 \%}$ \\
\hline $\mathbf{3}$ & Almost weak (almost up to none). & $\mathbf{6}$ & $\mathbf{2 0 \%}$ \\
\hline
\end{tabular}

The results of the interview also indicated that the role of the faculty member in upgrading the reality of integrity in Jordanian public universities is a leadership role and is linked to multiple fields, including the field of personality, as the most interacting things with academic integrity are the personal issues represented by how much the person believes in the value of integrity and thus raises the efficiency of work and employees in the environment He works with him, and as the cultural background affects the habits, values, and deviations in society that affect the individual, so that behaviors that can be negative or positive, or that the political field is overwhelmed, follow the extent to which this person is affected by partisan or parliamentary issues or the surrounding circumstances so as to prevent the existence of integrity Or pay to its existence, from the contractual or religious point of view, they are issues that may impose on this person matters of integrity in the sense of religion, which is often in the interest of individuals and the community, and finally in terms of technology and the digital economy, which is related to identifying matters with scientific digital issues that are set aside A year of mental modeling that overwhelms all issues of values and attitudes, and the proportion of faculty members agreed that the role of the teacher is related first to his commitment to According to the standards of transparency and fairness, and that his practices are directed towards academic integrity, to become a model for students to follow, by $53.33 \%$. This confirms the role of the faculty member in overcoming barriers, and that the faculty member must work to increase students' awareness of the importance of integrity through the human industry through dialogue and freedom to express opinion and respect for opinion and other opinion, the role of the faculty member is to re-dismantle the mental or mental On which the student grew up and reconsider the way of thinking, and the percentage of consensus on this opinion was about 26.66 as shown in Table No. (3). Also, the results of the interview showed that the faculty member should follow the regulations and instructions without arbitrarily toward the students, which is somewhat a missing link for some members of the faculty. Depending on the pressures, which leads to a disturbance of integrity. The percentage was approximately $10 \%$, as the results of the interview showed as shown in Table (3) that the role is related to the social behavior of the individual and his resistance to the challenges that may be exposed to it, according to the tribe according to the region to which the university belongs and is subject to social behavior and differs from one university to another accordingly, resulting in stresses Social that a faculty member may be exposed to despite his total rejection of the issue of integrity and as one of them stated that this is due to the system of internal values governing the faculty member ".... Deir Balak Aflan", which are statements against integrity and practiced by some not by conviction but by necessity and it was 10 It is a small percentage compared to the positive role that covers $53.3 \%$. Which requires him to do a number of things, the most important of which are: sincerity which is the pinnacle of integrity, 
renewed science and building critical academic sense, justice in dealing with marks, distance from racial and regional affiliations, and psychological satisfaction that lies in giving the lecture a complete aspect.

Table (3) what is the role of the faculty member in upgrading the status of integrity in the official Jordanian universities?

\begin{tabular}{|l|l|l|l|}
\hline & $\begin{array}{l}\text { What is the role of the faculty member in upgrading the } \\
\text { reality of integrity at the University of Jordan? }\end{array}$ & Repetitions & percentage \\
\hline $\mathbf{1}$ & $\begin{array}{l}\text { To adhere to transparency and fairness, and to put his } \\
\text { practices in the direction of academic integrity into a } \\
\text { model for students to follow. (Example) }\end{array}$ & $\mathbf{1 6}$ & $\mathbf{5 3 . 3 3 \%}$ \\
\hline $\mathbf{2}$ & $\begin{array}{l}\text { Work to dismantle the student's mentality and rebuild it } \\
\text { through (human industry) through dialogue and to } \\
\text { produce a generation that believes in scientific integrity. }\end{array}$ & $\mathbf{8}$ & $\mathbf{2 6 . 6 6 \%}$ \\
\hline $\mathbf{3}$ & $\begin{array}{l}\text { Follow the regulations and instructions without } \\
\text { discrimination or abuse. }\end{array}$ & $\mathbf{3}$ & $\mathbf{1 0 \%}$ \\
\hline $\mathbf{4}$ & $\begin{array}{l}\text { The role is related to the social behavior of the } \\
\text { individual according to the clan and the social behavior } \\
\text { by region. }\end{array}$ & $\mathbf{3}$ & $\mathbf{1 0 0 \%}$ \\
\hline Total & &
\end{tabular}

The results also showed that there are obstacles that limit the application of integrity in public Jordanian universities, which pose challenges for faculty members. When the faculty members were asked, "the subject of the study," it was found that there were obstacles faced by the faculty member, the most important of which was wasta and ethnic affiliations. The study sample agreed on it by nearly $70 \%$, and that the percentage of such a percentage is a dangerous indicator that predicts the existence of corruption that requires a process of reforms that begins with a community culture and ends with educational requirements that the university must adopt to limit its existence, and corruption cannot be fought if there is no effective will from all institutions of society and the trend towards preventive measures that reduce corruption and the surrounding environment. The results of the interviews on this question showed that $26 \%$ believe that there are obstacles, but that they do not constitute a phenomenon that requires concern and that they can be overcome by specialized committees (legal entities) or through community partnership through an educational role That starts from the family, and rethinking the concept of citizenship through a societal system that includes competencies, taking into consideration the obstacles faced by the universities of the parties more than others. Knowledge, creation, knowledge and commitment), while the percentage was very low about the answer, there are no obstacles by $3.33 \%$, as the reality indicates the opposite and unanimously, and the answer may be without the type of affiliation that the faculty member aspires to, that there is no impediment to applying integrity except not Applied.

Table (4) Are there obstacles that limit the application of a culture of integrity at the University of Jordan from your point of view as a faculty member or as an academic leader? What are the ways to overcome these obstacles?

\begin{tabular}{|l|l|l|l|}
\hline & $\begin{array}{l}\text { Are there obstacles that limit the application of } \\
\text { a culture of integrity at the University of Jordan } \\
\text { from your point of view as a faculty member or } \\
\text { as an academic leader? What are the ways to } \\
\text { overcome these obstacles? }\end{array}$ & percentage \\
\hline $\mathbf{1}$ & $\begin{array}{l}\text { Yes, there are obstacles, the most influential of } \\
\text { which is wasta, then race. }\end{array}$ & $\mathbf{2 1}$ & $\mathbf{7 0 \%}$ \\
\hline $\mathbf{2}$ & $\begin{array}{l}\text { The basic principle of integrity is that there are } \\
\text { obstacles that can be overcome. }\end{array}$ & $\mathbf{8}$ & $\mathbf{3 . 3 3 \%}$ \\
\hline $\mathbf{3}$ & $\begin{array}{l}\text { There is no impediment to the application of } \\
\text { integrity, and its non-application is the } \\
\text { impediment. }\end{array}$ & $\mathbf{1}$ & $\mathbf{1 0 0 \%}$ \\
\hline Total & & $\mathbf{3 0}$ & \\
\hline
\end{tabular}


As for talking about the role of the official Jordanian universities departments in developing a culture of integrity in it, it was divided into two parts: a preventive role and a therapeutic role, while the preventive role is to prevent the interference of favoritism and intermediaries in appointments, and to enhance computer technologies and link universities and scientific journals with one network to ensure arbitration in accordance with standards International inside and outside Jordan to ensure the efficiency and integrity of scientific research. It also includes building thinking and awareness by affecting students, while the therapeutic role lies in strengthening the role of social institutions, then the role of the Ministry of Education and renewing and tightening penalties and requirements for accepting scientific research, while one of the faculty members indicated that the strength of the state lies in its environment (its society) It is the so-called tripartite structure that resides in (women, education and children) and therefore society will produce strong leaders, and to activate this academically, departments must amend the university admission system, and be the link between universities and society by creating what is called the independent director in terms of science, ethics, Knowledge, and skills: "A man who does not understand life does not deserve to lead it."

The results showed an agreement of $70 \%$ on the role of university departments to develop integrity in the official Jordanian universities "under study" in terms of applying laws and regulations and limiting the mediation process through deterrent penalties and dealing with all university employees, students, teaching bodies and administrative bodies with justice and transparency in accordance with the regulations without exceptions Remember that everyone is equal and that the university's administration from all its employees is at the same distance. It was also evident from the results of the interview on this question, with a rate of $20 \%$, on the previous role of socialization institutions and that it is the basis upon which all roles are built in the future, as the educational role begins through family formation for individuals and community partnership in building a culture of integrity, after which universities work with their departments and cadres on The development of this culture after construction, and strengthened by wise academic leaders who do the initiatives that enhance the feeling of citizenship and fight corruption, which is what one of the members of the study sample called (the forces of reverse pulling against wasta from top to bottom and from bottom to top) .. As guidance is provided through continuous dialogue with The student, as for the support of the faculty member and the activation of technology in evaluation to reduce corruption and evaluation is through the administrative body and students, the proportion of the answers of the corresponding sample as shown in Table (5), 10\%, although giving the faculty member a full space in the issue of teaching without Reservations is one of the foundations of enhancing integrity and the necessity of having a faculty member in the evaluation committee in terms of marks, and focusing on the material aspect that displaces the burden on the faculty member and does not make him vulnerable to It occurred within any aspect of corruption, and some emphasized the need to computerize the scores system to exempt a faculty member from the excesses and pressures that he is exposed to, as the use of technology reduces corruption.

Table (5) What is the role of the university administration in developing integrity in the University of Jordan (proposals?)

\begin{tabular}{|l|l|l|l|}
\hline & $\begin{array}{l}\text { What is the role of the university administration in } \\
\text { developing integrity in the University of Jordan (proposals)? }\end{array}$ & Repetitions & percentage \\
\hline $\mathbf{1}$ & $\begin{array}{l}\text { Enforce laws and regulations and limit the mediation process } \\
\text { by deterrent penalties. }\end{array}$ & $\mathbf{2 1}$ & $\mathbf{7 0 \%}$ \\
\hline $\mathbf{2}$ & Enhancing the role of socializing institutions. & $\mathbf{6}$ & $\mathbf{2 0 \%}$ \\
\hline $\mathbf{3}$ & $\begin{array}{l}\text { Supporting faculty member, and activating technology in } \\
\text { evaluation to reduce corruption. }\end{array}$ & $\mathbf{3}$ & $\mathbf{1 0 \%}$ \\
\hline Total & & $\mathbf{3 0}$ & $\mathbf{1 0 0 \%}$ \\
\hline
\end{tabular}

The second question: What are the challenges that prevent the development of a culture of integrity in Jordanian universities from the viewpoint of faculty members?

Through answering the first question and analyzing the results of the interviews, it is clear that there are challenges and obstacles facing public Jordanian universities, but the competencies and awareness of the faculty members are an effective aspect in resisting and overcoming them, in the event that they are able to have qualified departments that lead the educational process with integrity and can identify competencies and men The right place in the right place, and taking decisions that will fight corruption and affect the culture of the university community through an atmosphere of justice. 
Accordingly, the faculty member's role side by side with the university's departments helps in overcoming challenges and is represented in the following:

First: The faculty member: to have a leading leadership role in change and the initiative for change, and that he himself commit to transparency and justice, and that his practices should be directed towards academic integrity, and away from racial and regional affiliations.

Second: Universities Departments: To perform their roles of the supervisory and preventive role, the therapeutic role, and the training role. In addition to activating the community partnership. According to the regulations and instructions, and amend them if necessary.

As for ways to overcome challenges, it is: to put instructions that can be applied, and not be just slogans. Equality in the application of the law, maintaining the prestige of the faculty member, and abolishing the principle of ignorance (support your brother unjust or wronged) change the culture of society. And stop interfering with intermediaries, whether academic or non-academic. Providing a space of freedom and confidentiality in the complaint, evaluating the faculty member away from personal relationships, activating the use of technology to reduce corruption, raising admission criteria in universities, and selecting departments away from patronage.

To achieve the previous goals and develop a culture of integrity in the official Jordanian universities, faculty members emphasize the need to achieve educational requirements through which the integrity standards (justice, transparency, accountability, and equal opportunities) are achieved through knowledge of the challenges and obstacles that prevent the achievement of these requirements, and thus work to overcome them. Treat them and start applying them on the ground.

\section{Recommendations}

Recommendations Based on the previous results, the study recommends:

Adopting educational requirements as a guide for developing a culture of integrity in universities.

Assigning competencies within the framework of transparency and equal opportunities away from favoritism.

Reconsidering the basis for admission of graduate students, and to be closely related to the outputs needed by local and international community institutions.

Attention to studies that measure the extent of challenges that impede the progress of the educational process in all fairness, transparency and fairness

Conducting comparative studies between Jordanian universities and international universities that have overcome challenges in achieving integrity.

\section{References}

Bani Sakher, Muhammad Khaled Odeh (2017). The degree of department heads practice ethical leadership and its relationship to the level of organizational integrity they have in Jordanian universities. Master Thesis, The Hashemite University, Amman, Jordan.

Jasem, Suhad Adel, Sabri, Hussam Mwafak (2015). Establishing the concept of integrity in university education: an academic map to enhance integrity in the concepts of public relations, Journal of the College of Arts, University of Baghdad, College of Arts 2015 (30), September 11, 2015.511-536.

Al-Hijaz, oday Jawad (2011), the methodological foundations of the educational media function in disseminating a culture of integrity. Journal of the Integrity and Transparency Authority for Research and Studies, (3). 2011,10 .

Al-Harbi, Muhammad bin Ahmed (2012), degree of commitment to the practice of administrative transparency in academic departments in the College of Education at King Saud University, a rigorous study. Specialized Educational Journal, 1 (6), 341-308.

Al-Harbi, Marwan bin Ali (2016). Determinants of violating academic integrity standards for undergraduate and higher university students in the Kingdom of Saudi Arabia. Journal of Humanities and Social Sciences, (39), Thesis, 207-280.

Al-Hayali, Nour Tareq (2013). The role of the university professor in spreading the culture of integrity, transparency and combating corruption, the proceedings of the Seventh World Conference, manifestations of corruption and its economic and social repercussions and ways to address them in Iraq, Basra.

Al Sean, Adel Abdel-Aziz (2011). The role of organizational culture and social justice in the fight against corruption, workshop on developing the legal and administrative skills of the leadership and its effects in the fight against corruption, Sharjah, 313-340.

Al-Taie, Youssef, Abdullah, Haroun, Rashid, and Raya (2017). Ethical Leadership and its Role in Organizational Integrity to Reduce the Nutrition of Administrative Corruption, "An Empirical Study on a Sample of the 
Departments of Najaf al-Ashraf," University of Human Development Journal, 3 (2), June 2017, pp. 272 311

Fadloun, Al-Zahra (2017). Total quality management as one of the mechanisms for promoting a culture of integrity in the university institution. Humanities Journal. Algeria. Umm Al-Bouaghi University. 28)): 124-111.

Al-Mobaideen, Muhammad Ahmed, Al-Anati, Khatam Abdulaziz, Badr Khan, Sawsan (2017). The role of Jordanian universities in enhancing the values of integrity and its relationship to affiliation with public and private university students, Educational Sciences Studies, 44 (4), 2017.

Nasser, Ibrahim (2004) Moral Education, (1st edition), Amman: Dar Wael for Publishing and Distribution.

Alkayed. H \&Alqudah. $M$ (2019) The Reality of Moral Behaviors of the Administrative Employees in the University of Jordan from the Students' Perspective, Dirasat: Educational Sciences, 46(1), 239-250.

Al-Shami, S Al-Qudah, M. (2020) Teaching Against Extremist Ideologies Through Evidence Obtained from the Holy Quran, ,Journal of Education and Practice, 11(13): 122- 128.

Al-Tamimi, A \& Al-Qudah, M.A (2019) The Relationship between the parenting Styles of the Students of the First Three Grades with their Level of Creativity, An Interdisciplinary Journal for Science and technology Studies, (13)1:123-134

Al-Turk. R, Al-Qudah, M. (2017). The Jordanian Universities Students Practicing Degree of Thinking Skills, Dirasat: Educational Sciences, 44(4),6: 73-91.

Al-Zoby, K \& Al-Qudah, M, (2020) Promoting Positive Behaviors among the Lower Primary School Students, Journal of Education and Practice, 11(8): 89-102.

Ben Tarif, E \& Al-Qudah, M. (2019). International Journal of Advanced Science and Technology The Reality about the Educational Capabilities of the Jordanian Women in preventing their Sons / Daughters from Adopting Fanatical Ideologies, Journal of Advanced Science 13(4):214-227

Al-Hammad, A \& Al-Qudah, M. (2019). Role of Jordanian Universities in Educating Students on Entrepreneurship from the Point of View of Juggling Students, An Interdisciplinary Journal for Science and Technology Studies, 13(1): 167-180

Al-Qudah, M (2006). The Relationship between Family Socialization Patterns and Some Personality Attributes of Female Undergraduates at Mu'tah University, Jordan Journal of Educational Sciences, 2(3): 155-168.

Brenda M.stoez1 and Anastassiya Yudintseva1,2 (2018). Effectiveness of tutorials for promoting educational integrity; a synthesis paper, Centre for the Advancement of Teaching and Learning. . Received: 30 May 2018 Accepted: 21 August 2018.

Denisova, E. (2018), Corruption, the Lack of Academic Integrity and Other Ethical Issues in Higher Education: What Can Be Done Within the Bologna Process, European Higher Education Area: The Impact of Past and Future Policies, pp 61-75 Cite as, First Online: 04 July 2018.

Eaton, S.E. and Edino, R.L. (2018), Strengthening the research agenda of educational integrity in Canada: a review of the research literature andcall to action, Eaton and Edino International Journal for Educational Integrity, 1February 2018. 5:14.

Fallouh, R \& Al-Qudah, M (2020) The Capability to Predict the Behaviors of the Students Enrolled in Jordanian Universities Through Their Aesthetic Values, Journal of Education and Practice, 11(4): 104-114.

Malkawi, S \&Al-Qudah, M. (2018, 1). Reality and Obstacles of the Partnership between Family and School in Jordan, Modern Applied Science, 2(12), 81-92.

Malkawi, S \&Al-Qudah, M. (2018, 2). The Reality of Partnership Between The Family and The School from The Perspective of Teachers' Working in Irbid First Education Directorate, Dirasat: Educational Sciences,45(3): 209-225.

Mohammad, A \& Al-Qudah, M, (2020), The Impact of Social Media on Unethical Behaviors from the Perspective of the Ninth and Tenth Grade Students in Jordan, Journal of Education and Practice, 11(15). 116-128.

Hatahet. F \&Alquda, M. (2016). Family Problems Experienced by Students of the University of Jordan, European Scientific Journal (12)13: 145-156

Rahamneh, K. F. A., and Al-Qudah, M., A. H. (2016), A Proposed Educational Vision for Activating the Role of the Jordanian Universities Students Families in Enhancing Students Intellectual Security from the Students Perspective, European Scientific Journal, 12(16):1857-7881.

Randall. Ken. Denise, G. Bender and Diane, M. Montgomery. (2007), Determining the Opinions of Health Sciences Students and Faculty Regarding Academic Integrity. International Journal for Educational Integrity 3.2, 27-40.

Qamweh, M \& Al-Qudah, M (2017) A Proposed Educational Guide to Help Working Woman to Match between Works and Raising Children, Dirasat: Educational Sciences, (44)4, 6: 109-139. 
Electronic references:

- (Al-Rai, 2019) http://ujnews2.ju.edu.jo/Lists/News/Disp_FormNews1.aspx?ID=9589 Accessed Thursday $8 / 1 / 2019$.

Ministry of Higher Education (2019). Available at http://www.mohe.gov.jo/ar/Statistics/Statistics2016-2017.pdf accessed Thursday. 10/10/2019 at $6 \mathrm{pm}$. 